Brit. J. prev. soc. Med. (1976), 30, 36-39

\title{
Trace elements in water and congenital malformations of the central nervous system in South Wales
}

\author{
M. S. MORTON \\ Tenovus Institute \\ P. C. ELWOOD AND M. ABERNETHY \\ MRC Epidemiology Unit, Cardiff
}

\begin{abstract}
Morton, M. S., Elwood, P. C., and Abernethy, M. (1976). British Journal of Preventive and Social Medicine, 30, 36-39 Trace elements in water and congenital malformations of the central nervous system in South Wales. The concentrations of $\mathbf{2 0}$ trace elements were determined by atomic absorption spectrophotometry on representative samples of tap-water collected from 48 local authority areas in South Wales. The associations between twelve trace elements and central nervous system (CNS) malformation rates for the 48 areas were examined. Significant correlations for four trace elements were observed. Of these, Al was positively correlated while for the remaining three- $\mathrm{Ca}, \mathrm{Ba}$, and $\mathrm{Cu}-$ negative associations were found. Regression analysis of the data suggested that the relationships between $\mathrm{Ba}$ and $\mathrm{Cu}$ with CNS malformation rates were more important than those of $\mathrm{Al}$ and $\mathrm{Ca}$.
\end{abstract}

There are large regional differences in the incidence of congenital malformations of the CNS in the British Isles (Edwards, 1958; Rogers, 1969; Elwood, 1970), and for South Wales in particular marked local area differences have been reported (Laurence, Carter, and David, 1968; Richards, Roberts, and Lloyd, 1972).

Penrose (1957) first made the suggestion that 'the geographical variations observed in the incidence (of anencephalus) might suggest ..... a causal agent, such as the presence or absence of trace elements in the water supply'. Following this suggestion Fedrick (1970) found that the incidence of anencephaly in 10 areas of the United Kingdom was negatively correlated with the total hardness, $\mathrm{pH}$, and to some extent the sodium content of the local water supply.

In the same year Stocks (1970) demonstrated that death rates of women aged between 25 and 54 years from cardiovascular diseases show a closely similar regional distribution in England and Wales as that for neural tube malformations. This is of interest since mortality from cardiovascular disease in the county boroughs of England and Wales has been shown to be strongly associated with the softness of their water supplies (Crawford, Gardner, $\frac{0}{3}$ and Morris, 1968a, b), although Roberts and Lloyd (1972) recently suggested that this association is a secondary (non-causal) one.

In contrast to the findings cited above, Fielding and Smithells (1971) observed that for several ${ }_{\sigma}^{\circ}$ towns in south-west Lancashire, the incidence of 3 . anencephalus has so far shown no relationship with water hardness. Similarly Wilson, Watson, and $\frac{\circ}{3}$ Richards (1973) investigating the possible relation- 0 ship between area difference in anencephaly in Glasgow and water supply concluded that acidity, $\vec{O}$ hardness, and metal concentrations (lead, copper, zinc, and iron) were not responsible for the area $N$ difference.

However, with particular reference to South Wales, Lowe, Roberts, and Lloyd (1971), dividing $\omega_{\sigma}^{\omega}$ the region into 48 local authority areas, reported a negative correlation between the incidence of CNS malformations and the total hardness of the related water supply. An analytical epidemiological ${ }^{+}$ study was made of the problem and such a study forms the basis of this report. 


\section{Materials AND Methods}

Hardness of water is a crude measurement of total calcium and magnesium levels which give little or no information about other elements which may be present (data from this study which have been presented elsewhere show that although for most elements correlations between 'hardness' and separate trace metal concentrations are significant, only that for calcium is really high (Elwood, Abernethy, and Morton, 1974). The present study was initiated to examine in detail any relationships there may be between area difference in CNS malformation rates in South Wales and the concentrations of 20 elements in the domestic water supply.

The area surveyed was exactly as that defined by Lowe et al. (1971) from which data for the incidence of neural tube malformations were taken. For direct comparison purposes the same division into 48 local authority areas was also maintained.

Within each of the 48 areas, 20 electors were selected at random and each was asked to draw two samples of tap water during a day in July 1973. To obtain the first sample the subject was asked to fill a clean jug with the first run-off from the kitchen tap, and from this to fill a polystyrene sample bottle (30 ml, Sterilin Limited, Surrey). Another sample bottle was to be filled at any time during the evening. Altogether 20 pairs of samples were requested within each area, at least 15 pairs were actually obtained, and in most areas 18 or more were returned. All the morning samples from each area were then pooled into high-density, acid-washed polythene bottles (1 litre Kernick \& Sons, Cardiff). The evening samples from each area were similarly combined.

The bulked samples were then treated with Aristar concentrated nitric acid (to give a nitric acid concentration of $2 \% \mathrm{v} / \mathrm{v}$ ) and stored at $3^{\circ} \mathrm{C}$ before analysis.

\section{REAGENTS}

All reagents used were of analytical grade and working standards for atomic absorption were freshly prepared each day from commercially available (May and Baker or British Drug Houses), bulk standards (1000 ppm) diluted with de-ionized water (prepared from Elgastat 2000 De-ionizer fitted with a C810 barrel, supplied by the Elga Group, Buckinghamshire).

\section{INSTRUMENTATION AND Methods}

The concentrations of 20 trace elements $(\mathrm{Na}, \mathrm{K}$, $\mathrm{Ca}, \mathrm{Mg}, \mathrm{Cu}, \mathrm{Mn}, \mathrm{Co}, \mathrm{Fe}, \mathrm{Zn}, \mathrm{Pb}, \mathrm{Cd}, \mathrm{As}, \mathrm{Ni}, \mathrm{Tl}$,
$\mathrm{Be}, \mathrm{Li}, \mathrm{Al}, \mathrm{Si}, \mathrm{Ba}$, and $\mathrm{Cr}$ ) were measured using a Varian-Techtron AA 1200 Atomic Absorption Spectrophotometer, fitted either with a standard air-acetylene burner or a Model 63 Carbon Rod Atomiser. The instrument was linked to a Smiths Servoscribe IS chart recorder.

\section{Statistical Methods}

Statistical analyses of these data were difficult, as the distributions for many elements were highly skew. A non-parametric technique (Spearmans rank correlation) was therefore used, followed by multiple regression analyses based on data transformed to $\log _{10}$. These methods are similar to those used in a parallel study derived from the same source (Elwood et al., 1974).

In drawing conclusions from a large series of correlations, there is an increased probability of statistical significance being achieved by chance alone in a few of the tests. An attempt to limit this occurrence has been made by considering the pairs of correlations based on morning and evening water samples together, and selecting for further consideration only those elements in which both are significant and consistent in sign.

\section{RESUlts}

The data for eight trace elements (As, Cd, Co, $\mathrm{Fe}, \mathrm{Ni}, \mathrm{Li}, \mathrm{Tl}$, and $\mathrm{Be}$ ) were discarded as the major proportion of the estimations were below the detection limit of the atomic absorption spectrophotometer. Data for the remaining elements ( $\mathrm{Na}, \mathrm{Mg}, \mathrm{Al}, \mathrm{Si}, \mathrm{K}, \mathrm{Ca}, \mathrm{Cr}, \mathrm{Mn}, \mathrm{Cu}, \mathrm{Zn}, \mathrm{Ba}$, and $\mathrm{Pb}$ ) were then analysed. The data for $\mathrm{Ba}$ should have been excluded as 14 of the estimations on morning samples and 11 on evening samples were below the limit of the instrument, but after assigning an arbitrary low level to these, certain correlations were found to be significant for this element and the data were subsequently included in most of what follows.

Table I shows that in general levels in the morning samples are more scattered and have higher means than the evening specimens, and for three elements $(\mathrm{Cu}, \mathrm{Zn}$, and $\mathrm{Pb}$ ) these differences may be important. Data from morning and evening samples are therefore kept separate throughout.

Analysis of the trace metal data with respect to CNS malformation rates (taken from Lowe et al., 1971) showed that four elements $(\mathrm{Al}, \mathrm{Ca}, \mathrm{Cu}$, and $\mathrm{Ba})$ were significantly correlated. Of these, $\mathrm{Al}$ was positively correlated with the malformation rates, while the remaining three elements were negatively correlated, (Table II). 
TABLE I MEANS AND STANDARD ERRORS OF TRACE ELEMENT ESTIMATIONS ON 48 SAMPLES OF TAP WATER BY TIME OF

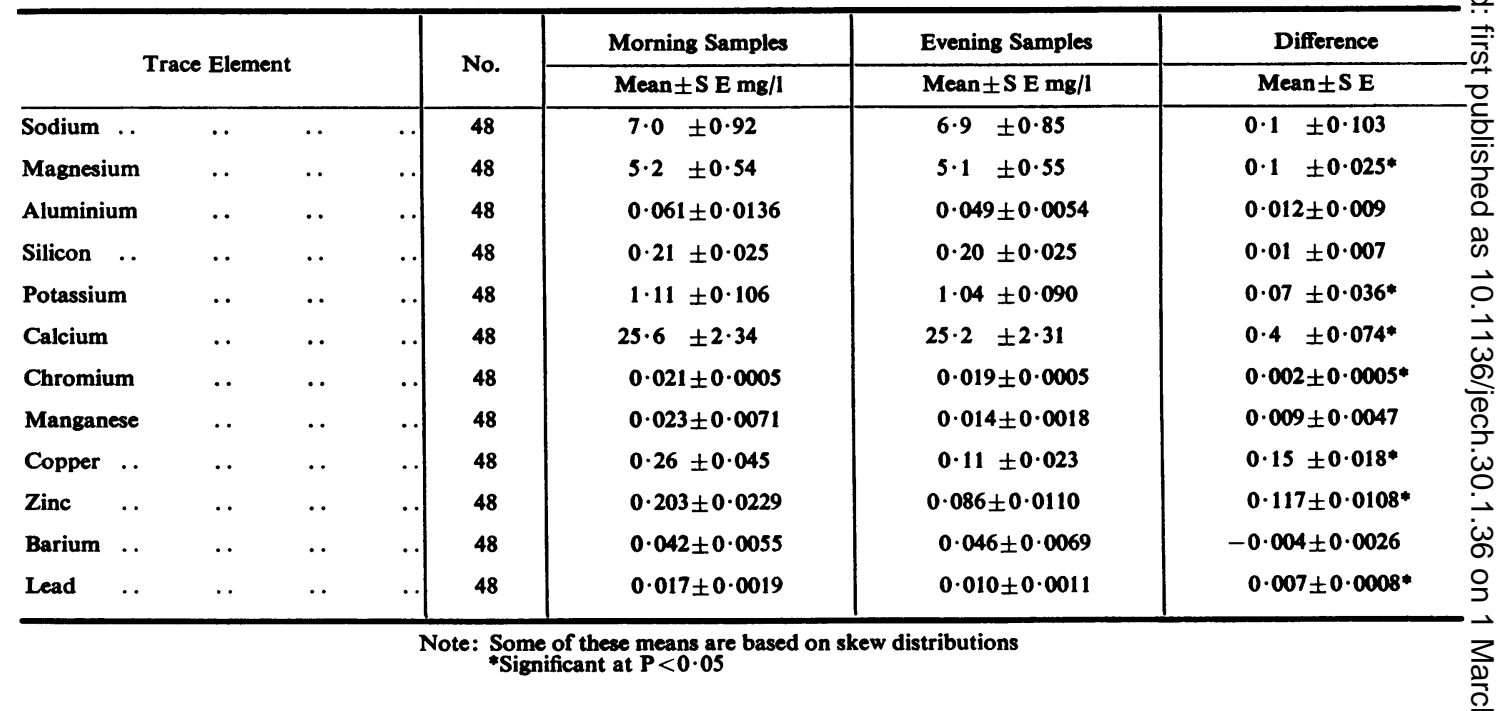

TABLE II

SPEARMAN'S RANK CORRELATION COEFFICIENT FOR TRACE ELEMENTS IN TAP WATER VERSUS CONGENITAL MALFORMATION RATES FOR 48 AREAS IN SOUTH WALES

\begin{tabular}{lll|c|c}
\hline \multirow{2}{*}{ Trace Element } & & \multicolumn{2}{c}{ Spearman's Correlation Coefficient } \\
\cline { 3 - 5 } & & & Morning Samples & Evening Samples \\
\hline Sodium &. &. & -0.284 & -0.285 \\
Magnesium &. &. & -0.150 & -0.129 \\
Aluminium &. &. & $0.305^{*}$ & $0.313^{*}$ \\
Silicon &. &. & 0.173 & 0.084 \\
Potassium &. &. & -0.111 & -0.139 \\
Calcium &. &. & $-0.297^{*}$ & $-0.308^{*}$ \\
Chromium &. &. & 0.084 & -0.144 \\
Manganese &. &. & 0.211 & -0.039 \\
Copper &. &. & $-0.418^{*}$ & $-0.376^{*}$ \\
Zinc .. &.. &.. & -0.140 & -0.087 \\
Barium &. &.. & $-0.330^{*}$ & $-0.458^{*}$ \\
Lead.. &.. &.. & -0.135 & -0.101 \\
\hline
\end{tabular}

*Significant at $\mathbf{P}<0.05$

Regression analysis showed an inconsistency in the signs for $\mathrm{Ca}$ and in the size of the coefficient for Al at the two times of sampling, which makes it unlikely that these two elements are important. $\mathrm{Cu}$ and $\mathrm{Ba}$ appear to be the most important elements in the context of CNS malformations, but only for $\mathrm{Cu}$ are the regressions significant for both the morning and evening samples. Copper alone explains about $16 \%$ of the variance in the malforni tion rate and the addition of $\mathrm{Ba}$ increases this $8 \circ$ about $19 \%$ in the morning samples and $29 \%$ in $\mathrm{tin}^{\sigma}$ evening samples.

\section{Discussion}

It is now generally agreed that atomic absorption spectophotometry is a most acceptable method of $\Rightarrow$ water analysis, offering sensitivity and accuracy to 3 research programmes demanding the analysis of many thousands of samples, some of which mayt have been stored for over two to three months under conditions of low temperature and $\mathrm{pH}$.

The data obtained from this survey are complex $x_{-}^{\vec{\sigma}}$ and our investigations are at a much too early 2 . stage to enable any firm conclusions to be drawn. Copper and Barium both have significant negative 3 associations; only $\mathrm{Cu}$ is fairly consistent in size at the two times of sampling. Although the association with $\mathrm{Ba}$ is less impressive than that with copper, the fact that a significant relationship was detected when about one-quarter of the areas had had too have an arbitrary low level of Ba assigned to them might suggest that an important relationship may exist between this element and CNS malformations $\omega$

It is of interest that elements that have attracted particular attention from animal teratologists have so far, in our investigations, shown no correlations with CNS malformation rates. Examples may be cited of experimental animals maintained on diets low in $\mathrm{Zn}$ (Warkany and Petering, 1973) or high 
in heavy elements such as $\mathrm{Pb}$ (Ferm and Carpenter, 1967), Cd (Chernoff, 1973) and As (Ferm and Carpenter, 1968) giving birth to malformed offspring although the malformations are not always of the central nervous system. In the light of such animal experiments, it would obviously be of tremendous value, although an enormous task, to determine the contribution that diet as a whole makes to the trace element status of the population in South Wales. Furthermore, valuable data might be obtained by measuring the trace element status of the blood of women in the early stages of pregnancy.

However, the data reported clearly indicate a need for further study, not only along the lines already employed, but also covering much wider aspects such as diet and maternal blood levels, and we are at present planning further studies throughout the United Kingdom in general and South Wales in particular.

The authors are grateful to the Tenovus Organisation for generous financial support and to Mrs J. A. McKinlay for expert technical assistance.

Requests for reprints: Dr M. S. Morton, Tenovus Institute for Cancer Research, Heath Hospital, Cardiff, South Wales.

\section{REFERENCES}

Chernoff, N (1973). Teratogenic effects of cadmium in rats. Teratology, 8, 29.

Crawford, M. D., Gardner, M. J., and Morris, J. N. (1968a). Mortality and hardness of local water supplies. Lancet, 1, 827.

water. Lancet, $1,1092$.

Edwards, J. H. (1958). Congenital malformations of the central nervous system in Scotland. Brit. J. prev. soc. Med., 12, 115.

Elwood, J. H. (1970). Anencephalus in the British Isles. Develop. Med. Child Neurol., 12, 582.
Elwood, P. C., Abernethy, M., and Morton, M. S. (1974). Mortality in adults and trace elements in water. Lancet, 2, 1470.

FeDrick, J. (1970). Anencephalus and the local water supply. Nature, 227, 176.

Ferm, V. H. and CARPenter, S. J. (1967). Development malformations resulting from the administration of lead salts. J. exp. Molec. Path., 7, 208.

_ and - (1968). Malformations induced by sodium arsenate. J. Reprod. Fertil., 17, 199.

Fielding, D. W. and Smrthells, R. W. (1971). Anencephalus and water hardness in south-west Lancashire. Brit. J. prev. soc. Med., 25, 217.

Laurence, K. M., Carter, C. O., and David, P. A. (1968). Major central nervous system malformations in South Wales. 1. Incidence, local variations and geographical factors. Brit. J. prev. soc. Med., 22, 146.

LOWE, C. R., RoberTs, C. J., and Lloyd, S. (1971). Malformations of the central nervous system and softness of local water supplies. Brit. med. J., 2, 357.

Penrose, L. S. (1957). Genetics of anencephaly. J. ment. Defic. Res., 1, 4.

Richards, I. D. G., Rober TS, C. J., and LlOYd, S. (1972). Area differences in prevalence of neural tube malformations in South Wales. A study of possible demographic determinants. Brit. J. prev. soc. Med., $26,89$.

ROBERTS, C. J. and LloYd, S. (1972). Association between mortality from ischaemic heart-disease and rainfall in South Wales and in the country boroughs of England and Wales. Lancet, 1, 1091.

ROGERS, S. C. (1969). Epidemiology of stillbirths from congenital abnormalities in England and Wales, 1961-1966. Develop. Med. Child Neurol., 11, 617.

STOCKs, P. (1970). Incidence of congenital malformations in the regions of England and Wales. Brit. J. prev. soc. Med., 24, 67.

Warkany, J. and Petering, H. G. (1973). Congenital malformations of the central nervous system in rats produced by maternal zinc deficiency. Teratology, 5, 319.

Wilson, T. S., Watson, R. S., and Richards, I. D. G. (1973). Anencephaly and water supply - a study of the problem in Glasgow. Hlth Bull. (Edinb.), 31, 76. 